\title{
Kütüphaneciyi Danışma Masasından Pazarlama: Reklam Aracı Olarak Hizmet Noktaları
}

\section{Selling the Library from the Reference Desk: Service Points as Advertisements}

\section{Sarah Reneker Andreen}

Günümüzde ve çağımızda insanların her şeyin İnternet'ten elde edilebileceğine, kütüphanelerin ve kütüphanecilerin soyunun tükenmekte olduğuna inandığı bir devirde, çalışan herkesin kütüphaneyi tanıtmada etkin olması, kendisini buna adaması gerekmektedir. Bu, bütün personelin zamanını, kütüphane için akılda kalan hoş sloganlar üretmeye, promosyonel metinler hazırlamaya harcanması anlamına gelmese de, kütüphanenin içeride ve dışarıda herkese satışı için topyekûn harekete geçmeyi anlatmalıdır. Kütüphanenin etkin promosyonu güç bir denge olgusudur; kullanıcıyı sunduğumuz hizmetlerle ilgili olarak bilgilendirdiğinizi düşünürken, çalışan personelin kütüphaneyi tanıtma çabası içinde, bu hizmetleri aksatmadığından da emin olmaIısınız.

Bugünlerde Borders ve Barnes and Noble gibi kitapçıllardan, İnternet ve Amazon'a uzanan bir rekabetle yüz yüze olduklarından, kütüphanelerin güçlü pazarlama stratejilerine her zamankinden daha çok gereksinimleri vardır. Insanlar Internet'e kolay erişimle, evlerinden çıkmadan istedikieri bilgiye giderek daha rahat ulaşabiliyorlar. Akademik ortamlarda öğretim elemanlarının ve öğrencilerin kütüphaneye gitmeden kütüphane veri tabanlarına ve hizmetlerine erişmeleri için yurtları ve büroları kablolarla donatma yönünde bir zorlama görülmektedir. Kütüphanecilerin de bildiği gibi, bilgiye erişme ve gereksinim duyduğunuz şeyi bulabilme, birbirinden bütünüyle farklı durumlardır. Kütüphaneciler, bugün de bilgi "gıda zinciri"nde anahtar rolünü oynamayı sürdürmekte ve daha önemlisi bu hizmetleri kullanıcılarına nasıl tanıtacaklarını öğrenmektedir. 
Kütüphane pazarlaması konusundaki literatür, hizmetlerimizin satışı için fiziksel kütüphanenin dışına çıkılmasının önemini göstermektedir. Arant ve Clark (1999), Library administration and management adlı makalelerinde şöyle söylemektedir: "Gerçekte kütüphanecilerin Evangelist bir yaklaşımla müşteriye kendilerini tanıtmak üzere bilgiyi kütüphanenin dışında da izłemeleri gerekir".

Çoğu kez, özellikle büyük halk ve üniversite kütüphanelerinde kütüphanenin pazarlama stratejisini ve halkia ilișkiler planını oluşturmak üzere bir komisyon kurulur. Üst yönetim kütüphanenin müşterilere nasıl satılacağı konusunda kararları verecek olan mercidir. Kütüphane literatürü, kütüphanenizin uzun dönemdeki başarısı için açık bir pazarlama stratejisi geliştirmenin önemini vurgulamaktadır. Yönetim de bütçeyi denetleyebildiği ve geniş çerçeveden bakabildiği sürece bu planı geliştirmelidir. Bu stratejinin uygulamaya konulması ile tüm çalışanlara planın bütünü ve hizmet amaçları açıklanır.

Bir pazarlama stratejisinin oluşturuıması ile kütüphanenin tanıtımı arasındaki farkın bilinmesi çok önemlidir. Kütüphane için pazarlama stratejisini, yönetim geliştirir. Doğru pazarlama kütüphanenin kullanıcı tabanını değerlendirmeyi, hangi hizmetlerin daha etkin olacağına karar vermeyi, fonları sağlamayı ve bunların yararlarını belirlemeyi içerir. Weingard'ın (1998) Future: Driven Library Marketing adlı kitabında belirttiği gibi "pazarlama, literatürde promosyon veya halkla ilişkiler dilinde tanımlamaktadır. Bu talihsiz bir yanııs anlaşılmadır; çünkü promosyon fonksiyonu pazarlama süreci içinde çok önemli olsa da, bu toplam çabanın yalnızca bir bölümü -son bölümlerinden bir tanesi- dür. Kütüphanecinin dikkati bütün bir pazarlama sürecinin yalnızca bir bölümü ile sınırlandığı zaman, pazarlama gerçekten yapılamamaktadır." Promosyonun tüm bir pazarlama sürecini içermediğinin önemle anlaşılmasına ek olarak bu makalede danışma kütüphanecisinin promosyondaki rolü irdelenmiş ve bilgi akışının danışma kütüphanecilerinden pazarlama ekibine -her iki yönde de- kütüphanenin pazarlama çabalarının başarısında ne kadar önemli bir rolü olduğu üzerinde durulmuştur.

Üst yönetim tarafından pazarlama stratejisinin geliştirilmesi, kütüphane hizmetleri için iyi bir plan oluşturulmasında etkin bir yol ise de uzun dönemde, kütüphanede çalışan herkes devreye girmediği sürece verimli olamaz. 
Personeliniz kütüphanenin hangi hizmetlerinin ve programlarının promosyonda olduğunu bilmediği sürece kulianıcılarını yeterince bilgilendiremezler. Bunun üzerinde düşünmeyi bırakın. Kütüphane kullanıcılarını en çok kim görüyor? Kütüphanenizdeki danışma kütüphanecileri ve halka hizmet veren personel. Halkla her gün karşılaşan ve yüz yüze gelen kütüphaneciler. Bu kişjler kurumun vitrinidir ve eğer kurumunuzun tüm yönlerinden haberdar olan seçkin kişiler değilse, bu kurumunuza kötü bir biçimde yansır.

Duckworth, Missouri Library World için yazdığı bir makalede, Springfield Green Country Library'nin pazarlama danışmanı Faith Popcorn'un pazarlama ve tüketici davranışı kestirimleri konusundaki fikirlerinden nasıl yaraslandığını tartışmaktadır. Bu süreçte kütüphanenin attığı ilk adımlardan biri, hizmetlilerden danışma kütüphanecilerinin başında bulunan amirlere kadar bütün personelin tüketici eğilimlerini inceleme kavramında yer almasını sağlamak olmuştur. Duckworth bu adımın ne kadar önemli olduğunu şöyle ifade etmektedir: "Projeye katılan personelin çoğu için geliştirilen fikirlerden daha önemlisi, bir paradigma değişiminin başlatılmasıdır. Kütüphane personeli, en önemli kaynağımız ise (ki, öyledir!); o halde kendimizi kütüphane hizmetini haritada gösterilmeyen bölgelere taşıdığımız ve 'kutunun dışında düşünmeye' başladığımız konusunda bilgilendirerek, hitap ettiğimiz topiumun benzersiz gereksinimlere nasıl karşılık vereceğimizi formüle edebilmemiz için zamanı iyi kullanmalıyı".

Bu nedenle kütüphane müdürü, halkla ilişkiler şefi ve/veya pazariama stratejisi geliştiren ekibe düşen, halka hizmet veren tüm personelin kütüphanenin uzun dönem amaçlarından, kütüphanenin hangi hizmetleri ve promosyonel olayları planladığından haberdar edilmesidir. İletişim basit gibi görünür, ancak pek çok kereler herkes personelin kütüphanede olup bitenlerin farkında olduğunu zanneder. Gerçekte durum böyle değildir. Genellikle yönetim sadece bilgilerin başkaları tarafından aktarıldığını düşündüğünden, kütüphane personeli kütüphanedeki gelişmeleri en son öğrenir. Zayıf iletişim her zaman suçludur, ancak insanların ya kendilerini üstün hissetmek ya da korumak için, sahip oldukları bilgileri saklama eğiliminde oldukları baz! zayıf fonksiyonlu kuruluşlar vardır. Bu değişmez bir biçimde iletişimin tamamen kırılmasına ve ha!kla ilişkiler hizmetinin zayıflamasına yol açar. Böyle bir kuruluşta 
iseniz, durumu düzeltmeye çalışabilirsiniz, ancak sorun tepe yönetimden kaynaklanıyorsa, en iyi seçenek başka iş fırsatlarını keşfetmeye başlamaktır. Yine de kuruluş yalnızca zayıf iletişimden yakınıyorsa, bu iletişim tıkanıkı ğı$\mathrm{nı}$ azaltacak bazı adımlar mevcuttur.

\section{Illetişim Araçları}

Kütüphanenizde iletişim hatlarının açık olmasını sağlayacak birçok yol arasında şunlar vardır: gazeteler, toplantılar, içeride dağıtılan görev listeleri ve personel odalarında veya bürolarında yapılan enformal iletişim. Bu seçeneklerin hepsi zamanınızı alacak ve kütüphanenin sınırlı kaynaklarını azaltacaktır ancak kütüphanede bütünüyle bir iletişim zayıflığı varsa bu yüksek düzeyde hizmet verip, kullanıcılardan destek almayı olanaksız kı|masa bile çok güçleştirir.

Gazeteler : Kütüphanelerden birçoğu kendi kullanıcı kitlesine ulaşım ve iletişim yöntemi olarak gazete çıkartmakta ise de, kütüphanede çalışan personel bir bütün olarak sürece dahil edilmedikçe, bir iki makaleye katkıda buIunsalar bile bu gazeteleri her zaman okuyamazlar. Kütüphane mensuplarına, kütüphanenin çıkarttığı gazeteyi okutmanın bir yolu, personeli de kullanıcılar gibi dağıtım listesine almaktır. Böylece çalışanlardan her biri kendi ga* zetesini alır ve boş zamanında okuyabilir. Bu gereksiz bir ek harcama gibi görülebilirse de personeli gündemden uzak tutmamak ve kütüphane meselelerine dahil etmek için oldukça yararlı bir yoldur. Fotokopi maliyetlerini fazła arttırmak istemeyen kütüphaneler için gazetenin dolaştırılması da sağlanabilir, ancak her zaman, yayının bir personelin masasının üzerinde çok uzun zaman kalma riski vardır.

Daha büyük kütüphaneler için etkin başka bir iletişim yolu da kurum içi gazetelerdir. Bir personel gazetesi çıkarılması oldukça zaman ve çaba gerektirse de, işlevsel olduğundan eski ve yeni personelin biyografilerinin paylaşımasında, kütüphane politikalarının tekrarında, yeni veri tabanlarının ya da dermeye katılan yeni kaynakların tanıtımında, kütüphaneyi etkileyen temel olayların anlatımında ve kütüphanede yapılacak toplantıları, promosyonları, etkinlikleri bildiren bir takvim formunda kullanılabilir. Gazeteler, kütüphane 
yenilikleri ve makaleler gibi mesleki gelişim kaynaklarının paylaşııması için de uygun araçlardır.

Masa üstü yayıncılık ve elektronik posta dağıtımının kullanıldığı bu çağda, bir gazete formatı oluşturup, bunu farklı kullanıcı grupları için uyarlamak oldukça kolaydır. Yayınlarınızı kullanıcı gruplarına uyabilecek şekilde hazırlamak kütüphaneyi hem içerde, hem de kullanıcılara tanıtmada etkin bir ortam yaratabilir. Weingard'a (1998) göre dikkate alınabilecek bir nokta daha vardır, "...iletilen mesaja dinleyicinin yanıtını almak için, bu iletişim sürecine bir geri bildirim halkası eklemek gerekiı". Kütüphane içinde ve dışında yayınlanan gazeteler okunmadıkları sürece yararlı değiłdirler. Danışma kütüphanecileri gazetelerin içeriğini ve yararlıı̆ını belirlemede yardımcı olabilecek kaynaklardan biridir. Onlar kullanıcıların kim olduğunu ve hangi tür kaynağı istediğıni bilirler. Bu personel aynı zamanda gazetede dağıtılan bir kitabın birdenbire çok popüler olduğunu da söyleyebilir. Eğer değilse, niçin değildir?

Hizmet masaları gazetelerin dağıtıldığı ve dağıtım listesine dahil olmak isteyenlerin adını yazdırabileceği noktalardır. Danışma kütüphanecilerinin görevlerinden biri de tüm kütüphane hizmetlerinin tanıtımı olduğu için, bu personel gazeteye bir göz atan kişiyi bile dağıtım listesine ekleyecek şekilde eğitilımelidir. Kullanıcılara sürekli hizmet sunulan bir danışma biriminde, formel danışma görüşmeleri olmasa bile, kütüphanenin yardımcı ve dost bir yaklaşımı olduğu imajı kazanılır.

Toplantılar : Toplantılardan kimse pek hoşlanmaz. Toplantılarda çok zaman harcanır ve genellikle çok yarar da sağłanamaz. Ancak iyi yönetilmiş bir toplantıda katılımcılar yeni kütüphane hizmetleri ve politikaları hakkında çok değerli bilgiler aktarılabileceği gibi, kütüphanedeki sorunlar ve olaylarla ilgili görüşme olanağı sağlanir. Danışma kütüphanecilerinin, kütüphanedeki yeni hizmetler ve programlarla ilgili geri bildirim verilerini yönetime iletmesi de çok önemłidir. kullanıcılar gerçekten yeni hizmeti kullanıyor mu? Yeni web ara yüzü karışıkıı yaratıyor mu? Kullanıcılar farkıı ürün ve hizmetler talep ediyor mu? Yeni yöneltme işaretlerinden nefret mi ediyorlar? kütüphanelerde çoğunlukla kullanıcılarının ne istediklerini ve neye gereksinim duyduklarını öğrenebilmek için yapılan kullanıcı araştırmalarına çok zaman ve para harcanır, fakat danışma masası çalışanları gibi, kullanıcıların günlük taleplerini kavrama durumunda olan grupla konuşup bilgi alma yoluna gidilmez. 
Hizmet masalarından alınan geri bildirim önemlidir, ancak kütüphane, çaıı̧̧anlarla düşüncelerini kolaylıkla söyleyebilecek bir toplantı ortamı yaratmazsa pazarlama ekibi birçok güzel fikirden yoksun kalabilir. Duckworth'ün (1998) kütüphane için yeni bir pazarlama stratejisi geliştirmesi üzerine yazdığı makalede belirtildiği gibi, çalışan kişilerin sürece dahil edilmesi esastır. "... hizmetlisinden bekçisine, bilgi kaynağı işlemcisinden danışma kütüphanecisine 50 kişi bu gelişme kavramına dahil edildi. 45 dakika içinde her bir grup, programlar ve hizmetlerle ilgili yaratıcı fikirlerle dolu bir liste hazırlamıştı. Yönetim kadrosu bu fikirleri aldı ve işledi".

Elektronik Posta : Elektronik posta (e-posta), hem dış dünya, hem de içerideki kullanıcılar için mükemmel bir iletişım aracıdır. Kütüphanelerin çoğu bu iletişim aracını gerektiği gibi kullanamamaktadıt. E-posta çok iyi bir promosyon yolu ve kütüphane personeli için de fevkalade bir dağıtım ortamıdır. Kütüphaneler hazırlayacakları elektronik gazete ile gelecekteki programlar, politika değişiklikleri, yeni veri tabanları ve kütüphane kaynakları ayrıca ilgili Internet sitelerj hakkında haber verebilirler. Kütüphane sistemi içinde e-postayı başııca iletişim aracı olarak görmek, kütüphane yönetiminin şube konumunda bile tüm çalışanlarła irtibatta olmasına imkan verir. Kütüphanecilerde güçlü bir toplum duygusu uyandırır. E-postanın düzenli olarak kullanılması, bütün bilgi işlem becerilerinin geliştirilmesini sağlayabileceği gibi, personeli, aksi taktirde dile getiremeyeceği sorunların ve olguların da paylaşılması için yüreklendirir.

\section{Hizmet Noktaları}

Fiziksel Yerleşim : Yeni bir kütüphane oluşturma devresinde bulunmadığınız sürece -bazen kurulma sırasında bile- danışma görevlilerinin hizmet masasının bulunduğu yer konusunda söyleyecek fazla bir şeyi bulunmaz. Danışma görevlileri, bu masanın kolay yaklaşılabilir, dost görünümiü ve göze kolaylıkla çarpan bir yerde kurulmasını sağlamalıdır. Zayıf yöneltme, kötü aydınlatma, danışma masasının üzerinde iş yığınları ve danışma masasına erişme güç|üğü kullanıcıyı istediğ bilgive ulaştırsa bile, kütüphane ve verdiği hizmetler hakkında olumsuz bir etki yaratılmasına neden olur. 
Yöneltme : Danışma ve hizmet masası çalışanlarının görevlerinden biri, yönetimi kütüphanedeki yöneltmelerin etkinliği konusunda bilgilendirmektir. Bџ kişiler gün boyunca kendilerine yöneltilen soruları cevaplandırdıklarından, kullanıcıların kütüphanede ne kadar kolay dolaştıklarını doğru olarak değerlendirebilirler. Danışma masası görevlileri sürekli tekrarlanan soruları not etmeli ve yöneltmelerin kullanıcıların yararlanacağı şekilde nasıl yerleştiriłmesi gerektiğini saptamaya çalışmalıdır. Daha sonra bu billgi yönetime aktarılır. Yönetimin konu ile ilgili kendi aldığı kararları alt kademelere iletmeleri son derece önemlidir. Çeşitli nedenlerle yeni bir işaretin konulması gerekli görülmeyebilir ancak bu karar çalışanlara iletilmezse, görevliler yalnızca önerilerinin dikkate alınmadığını düşünecekler ve kütüphane hizmetlerini iyileştirme yönündeki çabalarından vazgeçeceklerdir.

Erişim : Kütüphanedeki hizmet masaları ne kadar erişilebilir görünmektedir ve personel ne kadar dost yaklaşımlıdır? Bazen kütüphanelerdeki danışma masaları çok telaşlı olabilirse de, burada görevli personelin yeni gelenlere de hemen hizmet verecek biçimde eğitilmesi gerekir. Danışma kütüphanecisi bir telefon görüşmesinin veya daha farklı bir işlemin ortasında bile olsa gelen kişiye bakıp gülümsemelidir. Yalnızca bir göz teması sağlamak bile, kullanıcıya orada bulunduğunu ve görevlinin en kısa zamanda kendisin yardımcı olacağı duygusunu verir.

Danışma masasından görünüm nasıldır? Kütüphaneciler bilgisayar alanını görebiliyor mu? Gelen kullanıcıları görebiliyorlar mı? Kullanıcıların masanın etrafında rahatlıkla hareket edebilecekleri bir alan var mı? Bir danışma masasının tasarımını yaparken bütün bunların dikkate alınması gerekir ve bir kere yerleştirme yapıldıktan sonra, personelin pek fazla değişiklik yapma şansı kalmasa da yerleştirme hataları olduğunda bunları izlemeli ve düzeltilmesi için çaba gösterilmelidir. Örneğin eğer görüş açısı bir sorun ise, daha yüksek iskemleler kullanılarak kullanıcının kütüphaneciyi danışma masasında rahatfıkla görmesi sağlanır. Kütüphaneciler, atmosferi sürekli iyileştirme ve hizmet noktalarına erişimi kolaylaştırmaya çalışırken daha göz önünde bulunarak hizmetlerinin promosyonunu da gerçekleştirmelidir.

Broşürler : Kütüphanenin hizmet ettiği toplumla iletişim kurabileceği önemli araçlardan biri de broşürler ve diğer yayınlardır. Bütün hizmet masa- 
larında daima kütüphane planı, kütüphanenin genel hizmet ve politikalarını özetleyen bir broşür, ayrı bir kitapçık oluşturabilecek sayıda ise kütüphanenin elektronik kaynaklarını tanıtan bir broşür, kütüphane ile ilgili eğitim çizelgesini ve programlanan etkinleri içeren el ilanlarından bol miktarda bulunmaIıdır. Danışma kütüphanecileri, kullanıcılar için aylık takvimler geliştirerek hem kullanıcılarının yakında gerçekleşecek etkinliklerden haberdar olmalarını, hem de personelin yaklaşan programlar konusunda uyanık bulunmalarını temin edebilirler.

Danışma görevlileri kütüphane kullanıcılarından birçoğu ile en çok irtibatta bulunan kişiler olduklarından, bütün bu yayınları hazırlayabilirler. Kullanıcı hizmeti veren kütüphaneciler hizmet verdikleri toplumla etkileşimleri sırasında, broşürlerde yanıtı bulunmayan soruları da belirlemeye dikkat etmelidirler. Insanlar çoğu zaman masada dururken önlerindeki belgeyi okumadığı için, bu biraz güç olabilirse de, yalnızca kullanıcıları gözlemleyerek, bazı geri bildirimler elde edilebilir. Çalışan kişiler aynı zamanda kullanıcılar tarafından hem bizzat geterek, hem de telefonla düzenli olarak hangi soruların sorulduğunu izleyerek, bu soruların yanıtlarını, kütüphane hakkında bilgi veren kaynaklara ekleyebilir.

Kütüphane hizmetlerini tanıtan yayınları hazırlarken, irtibat kurulacak bilgileri de eklemek gerekir. Bir broşürü alıp eve götürdüğünüz zaman, bunun kim tarafından gönderildiğini ya da daha fazla bilgi için nereye başvurmanız gerektiğini belirlemek hoş değildir. Öncelikle kurumun adı belirtilmeli, ardından telefon numarası, adres, web sayfası adresi ve e-posta adresi gibi irtibat bilgileri yer almalıdır. Ayrıca yayının güncelliğini gösteren bir tarihin verilmesi de yerinde olur.

\section{Eğitim}

Har'ka!. Kütüphanede iyi bir iletişim var, personel kütüphanenin sunması gereken hizmetlerin bilincinde, bütün kütüphanede kullanıcıların gereksinmelerini karşllayabilecek bilgi verici broşürler ve yöneltmeler var, kütüphane yeni hizmetler vermek üzere önemli miktarda zaman ve para ayırmış bulunmaktadır. Yalnızca bir sorun kalıyor, kütüphane kullanıcılarından hiçbiri, yeni veri 
tabanları, bilgisayarları, fotokopi makinelerini ve gün içinde gerekli görülen diğer araç gereci nasıl kullanacağını bilmemektedir. Kullanıcıların eğitime gereksinimi vardır ve bu eğitimi verecek olan da danışma kütüphanecileridir. Birine yeni bir ałaç ya da yeni bir veri tabanı üzerine eğitim vermek için, öncelikle danışma görevlisinin bu kaynağı öğrenmesi lazımdır. Bu husus aşikâr olmakla birlikte, bilmecenin bir parçası gözden kaçmaktadır. Kütüphaneciler elde mevcut olanla idare etmekte veya bilmeleri gerekenleri öğrenmekte çok ustadırlar. Boğazınıza basan bır kullanıcıyı eğitmeye çalışırken araştırmayı kendiniz yapmayı istemeniz ilk defa olmuyordur. Bu kaynağın satıcısł basım anahtarını mı gizlemiştir ya da araştırma kart oynayanlar gibi bir yıldız veya ünlem işaretinin mi kullanımasını gerektirmektedir.

Çalışan personel kütüphanedeki seçenekler ve hizmetlerle ilgili yeterince bilgi sahibi olduktan sonra bu bilginin danışma masalarına taşınması önem kazanır. Bir kullanıcının sorununu en basit biçimde cevaplayarak, bir adım ilerlemeden ve olası seçenekleri sunmadan geçiştiren bir kütüphaneciyi duymak kadar sıkıcı bir durum olamaz. Örneğin: bir kullanıcı danışma masına yaklaşır ve sorar: "Kütüphanede Encyclopedia Britannica var mı?' Kütüphaneci yanıtlar, "Evet, kütüphanenin diğer tarafında, 2.geçitte". Bu teknik olarak doğru bir yanttır ancak bu ansikjopedi kütüphanede elektronik formda da bulunuyorsa ne olacak? Kullanıcı anahtar sözcükte taramasını yapabilir, aradığı bilgiyi basabilir ya da indirebilirdi. Kütüphaneciler çoğu kez kullanıcıya elektronik kaynaklardan söz etmemektedir. Bu önemli bir hatadır ve kütüphaneye uzun dönemde zarar verebilir. Kütüphaneçiler, kaynakların elektronik formda da mevcut olduğunu biraz da kullanıcının yanıtından çekinerek söylememektedir. Kütüphaneye gelen okuyucu o zaman yeni kaynakların kullanımını öğrenmek isteyecek, bu da danışma kütüphanecisine ek bir yük getirecektir. Ancak insanların farkında olmadıkları veya kullanmaları için eğitilmedikleri kaynaklara para harcamak da anlamsız olur.

Carpenter (1998), Computers in Libraries'deki makalesinde şöyle demektedir: "kütüphanelerimizi teknoloji yoluyla pazarlamak için öncelikle teknolojinin kendisini yararlı ve dost hale getirmeliyiz. İnsanlara her şeyin yönetimini öğrenmesini sağlayamayız, böylece yeni hizmetleri etkin bir biçimde ve boşuna uğraşmadan kullanabilirler... Müşteri hizmetini iyileştirmenin yollarından 
biri yarattığımız teknolojik ortamı sahiplenmek ve tüketicinin kullanımı kolaylaştırmaktır. Müşterilerinizi teknolojinin kütüphanede kullanılma sürecine dahil edin ve kullanımını öğretmeyi de üstlenin".

Yönetim, personelin yeni kaynaklarla ilgili eğitimi konusunda bu hizmetler daha da dibe vurmadan titiz davranmalıdır. Teknoloji satıcılarının birçoğu gelip hizmetlerini tanıtmada istekli olduklarından, topluluklarda birkaç eğitim programı yapmaları yönünde ikna edilebilirler. Bu iyi bir pazarık yetilerinin kullanımı gerektiren bir durumdur. Satıcılar kütüphaneye gelip eğitim verdikleri taktirde, ürünlerini daha çok kişinin kullanabileceği ve kütüphanenin aboneliğini devam ettirebileceği veya ek bir anlaşma daha yapabileceğine inandırılabilir. Bu strateji personeliniz ve hizmet verdiğiniz toplumu eğitme çabalarınızda mucizeler yaratabilir. Eğitim oimadan kütüphanenin pahalı ürünleri kullanılmayacak ve okuyucular sürekli olarak personel tarafından eğitilmedikleri için, kullanamadıkları yeni kaynaklarla karşı karşıya kaldıklarında, bu durum kütüphanenin topyekûn kullanıcı memnuniyetini azalabilecektir.

Danışma masasındaki en büyük hatalardan biri, personelin yeni bir veri tabanı, sistem ya da politika ile ilgili olarak kütüphane kullanıcılarına da yansıyacak şekilde huzursuz olmasıdır. Kütüphaneciler birçok defa danışma masasında yeni kaynaktan hoşlanmadığı veya daha doğrusu kullanmayı bilmediği ve kullanıcının önünde aptal durumuna düşmek istemediği için, karşılarındaki okuyucuya yardımcı olamamışlardır. Kütüphanenin yeni çevrim içi sistemi, 5000 kayıt alıyorsa ve personel düzgün bir çıktı almayı öğrenememişse, kaynak listesini işaretlemek eskisine göre üç basamak fazla işlem gerektiriyor, kullanıcı da orada şikayet edip duruyorsa, bunlar sistemin eleştirilmesini, kusurların sayılmasını oldukça kolaylaştırır. Gerçekte kullanıcıya istediğini veriyor gibi görünseniz de örneğin onunla aynı fikirde olmanız halinde, kullanıcı yine de kütüphane yönetiminin ne yaptığını bilmediğini, personelin de hizmet araçlarını kullanamadığını düşünecektir. Kütüphaneci neticede okuyucunun talep ettiği bütün kaynakları temin etse bile, gidecek olan bu mesajdır. Daha iyi bir yaklaşım kişiyi her hâlde dinlemek, fikirlerini kısmen paylaştığınızı ifade etmek, kütüphanenin yeni sisteminin veya hizmetinin daha iyi olduğunu açıklamak ve ona birlikte kullanmayı önermektedir. Burada deneyimli bir danışma kütüphanecisinin sakin ve yatıştırıcı ses tonu gerçek- 
ten önemli bir farklılık yaratır. Kütüphane kullanıcısı ile meşgul olurken ses tonunun ne kadar çok şey değiş̧irebileceği son derece şaşıtıcıdır. Kütüphaneci, kullanıcının yeni sistemle ilgili tatminsizliğini onaylarsa fitili iyice ateşlemiş olur. Okuyucunun kızgın olmaya hakkı vardır, yeni bilgisayarlar biraz daha karmaşık olabilir; ancak kütüphanedeki ürünlerle ilgili olarak iyi eğitilmiş, becerikli bir kütüphaneci durumu lehine çevirerek hem ürünü, hem de bütün olarak kütüphaneyi kullanıcıya pazarlamayı başarabilir. Bu tip bir yaklaşımı gerçekleştirmek güç olsa da, personel bu yönde eğitilirse dünya kadar fark yarattığı görülecektir. Kütüphane çalışanları yeni bilgisayarı eleştirip, kızgın ve rahatsız kullanıcılara hak verdikleri zaman, başlangıçta onlardan olumlu bir geri bildirim alabilirler; fakat kullanıcı tamamen kızgın ve rahatsı gitmese de içinde olumsuz fikirlerle ayrılır ve kütüphaneyi bir kez daha kullandığında etkin bir erişim sağlayamaz.

\section{Sonuç}

Kütüphane hizmetlerinin tanıtımı, kuruluşun başarısı için son derece önemlidir. Kütüphanenin çok iyi ve harika olduğu düşünülen günler çok geride kalmıştır. Kütüphaneciler, kütüphaneye giren her insana hizmetlerini tanıtmak üzere hazırlanmalı ve aktif olarak dışarı çıkıp yeni kullanıcılar aramalıdır. Danışma görevlileri öncelikle kütüphane içerisinde okuyucuya en yüksek düzeydeki hizmeti sağlayacak kişilerdir. Personel, kütüphanede bulunan bütün kaynakları kullanabilecek şekilde eğitilmeli ve yeni ürünlerin gerçekleştirilmesinde de yardımcı olmalıdır.

\section{Çeviren: Prof. Dr. Sekine Karakaş}

The Reference Librarian, Number 73, 2001, 281-292.

\footnotetext{
* Prof.Dr. : Ankara Üniversitesi Bigi ve Belge Yönetimi Bölümü Başkanı (akarakas@humanity.ankara.edu.tr).
} 